\title{
Kriminalisasi Perempuan Pekerja Seks Komersial dalam Perluasan Pasal Zina RUU KUHP
}

\section{Leony Sondang Suryani, ${ }^{1}$ Ani Purwanti ${ }^{2}$}

${ }^{1,2}$ Fakultas Hukum Universitas Diponegoro, Semarang email: leonysuryani@gmail.com; ani_purwanti81@yahoo.com

\begin{abstract}
This article discusses the Criminal Code Bill which has unjust legal potential because the provision of adultery has been extended to sexual acts by unmarried couples. This article presents an analysis of the possible implications of the Criminal Code Bill - specifically the section on adultery of sex workers through the socio-legal method in which a combination of normative legal approaches and social research methods is applied. This article states that broadly defined provisions of adultery can lead to unfair penalties -due to injustice- sex workers who by law must be treated as victims of sexual exploitation and fraud rather than perpetrators of crime.
\end{abstract}

Keywords: Criminal Code Bill; sex workers; criminalization

\begin{abstract}
Abstrak: Artikel ini membahas RUU KUHP yang memiliki potensi hukum yang tidak adil karena ketentuan perzinaan yang telah diperluas terhadap tindakan seksual oleh pasangan yang belum menikah. Artikel ini menyajikan analisis tentang implikasi yang mungkin dari RUU KUHP - khususnya bagian perzinaan pekerja seks melalui metode sosio-legal di mana kombinasi pendekatan hukum normatif dan metode penelitian sosial diterapkan. Artikel ini menyatakan bahwa ketentuan perzinaan yang didefinisikan secara luas dapat mengarah pada hukuman yang tidak adil -karena ketidakadilan keadilan- pekerja seks yang oleh hukum harus diperlakukan sebagai korban eksploitasi dan penipuan seksual daripada pelaku kejahatan.
\end{abstract}

Kata Kunci: $\quad$ RUU KUHP; pekerja seks; kriminalisasi

\section{A. Pendahuluan}

Prostitusi adalah praktik menjual dan/atau mendistribusikan layanan seksual sembarangan kepada seseorang yang bukan pasangan, dengan imbalan pembayaran langsung dalam bentuk uang atau barang berharga lainnya. ${ }^{1}$ Prostitusi umumnya dilakukan karena tingginya permintaan pasar dengan persyaratan profesional yang agak rendah yang sering menarik orang yang kurang

${ }^{1}$ M. H. Ditmore, Encyclopedia of Prostitution and Sex Work, vol. 1 (California: Greenwood Publishing, 2006), 1-3. 
terampil. ${ }^{2}$ Persepsi publik terhadap prostitusi beragam di masyarakat. Beberapa orang mungkin mengakui prostitusi sebagai suatu bentuk profesi, kebanyakan dari mereka menghindari, mencaci, dan menghukum pelacuran baik dari penyalur maupun klien- sebagai perbuatan ketidaksenonohan dan imoralitas. ${ }^{3}$ Di Indonesia -bersama dengan negara-negara lain pada umumnya-, prostitusi dianggap sebagai masalah sosial yang persisten di mana pemerintah telah meluangkan banyak waktu dan upaya untuk meminimalkan -jika tidak dapat menghapus praktik prostitusi. Meskipun beberapa penelitian menunjukkan bahwa prostitusi dapat memiliki dampak positif seperti untuk melokalisir ketidaksenonohan terus-menerus dan mengandung HIV/AIDS menyebar melalui seks yang tidak aman, prostitusi secara historis dianggap sebagai fenomena patologis dalam masyarakat yang dapat menodai moralitas sosial, norma, dan ketertiban yang ada. ${ }^{4}$ Menurut data statistik Kementerian Sosial RI, ada 5.000 pekerja seks perempuan yang telah menjalani rehabilitasi oleh pemerintah di seluruh Indonesia dalam tiga tahun terakhir. Pada tahun 2015, Direktorat Jenderal Rehabilitasi Sosial telah mencapai target untuk merehabilitasi 1.000 lebih banyak pekerja seks. ${ }^{5}$ Terlepas dari itu, pelacuran tampaknya mengungkapkan banyak segi dimensi sosial dalam sebuah peradaban yang tidak hanya tentang masalah-masalah seksual, tetapi juga masalah seksual.

Keberadaan prostitusi di Indonesia adalah subkultur peradaban modern, terutama di kota-kota metropolitan, karena ketegangan yang tinggi dan per-

\footnotetext{
2Baca: Lena Edlund dan Evelyn Korn, "A Theory of Prostitution," Journal of Political Economy 110, no. 1 (2002): 181-214, https://doi.org/10.1086/324390.

${ }^{3}$ Baca: Edlund dan Korn; Timothy J. Gilfoyle, "Prostitutes in History: From Parables of Pornography to Metaphors of Modernity," The American Historical Review 104, no. 1 (1999): 117-41, https://doi.org/10.2307/2650183.

${ }^{4}$ Baca artikel-artikel penelitian: Terence H. Hull, E. Sulistyaningsih, dan G. Jones, "Prostitution in Indonesia: Its History and Evolution," Bulletin of Indonesian Economic Studies 36, no. 1 (2000): 258-60; Riswanda, Yvonne Corcoran-Nantes, dan Janet McIntyre-Mills, "Re-framing Prostitution in Indonesia: A Critical Systemic Approach," Systemic Practice and Action Research 29, no. 6 (2016): 517-39, https://doi.org/10.1007/s11213-016-9379-2; Riswanda, Janet McIntyre-Mills, dan Yvonne CorcoranNantes, "Prostitution and Human Rights in Indonesia: A Critical Systemic Review of Policy Discourses and Scenarios," Systemic Practice and Action Research 30, no. 3 (2017): 213-37, https://doi.org/ 10.1007/s11213-016-9393-4.

${ }^{5}$ Harris Y. P. Sibuea, "Penegakan Hukum Prostitusi di Indonesia," Info Singkat Hukum: Kajian Singkat terhadap Isu Aktual Stategis 7, no. 10 (2015), www.dpr.go.id.
} 
saingan telah mengerahkan minat pada kebutuhan pelepasan ketegangan terhadap prostitusi yang ada. ${ }^{6}$

Menurut Edlund dan Korn,7 ada empat prasyarat prostitusi. Pertama, sebagian besar praktisi prostitusi kurang terdidik atau tidak adanya legitimasi pendidikan, yang karena itu kapasitas tawar mereka tidak cukup untuk bekerja di pekerjaan formal. Hal ini motivasi mereka untuk mengejar pekerjaan yang tidak membutuhkan latar belakang pendidikan sekalipun. Pekerjaan semacam itu tidak umum dikenal sebagai profesi, atau bahkan lebih buruk lagi, pekerjaan tidak senonoh. Kedua, tekanan ekonomi untuk menopang hidup seseorang adalah segera dan tidak henti-hentinya jika kondisi keuangan seseorang berisiko kebangkrutan atau terjerat dalam lingkaran utang dan kewajiban. Ketiga, tidak adanya inisiatif untuk mempertahankan keadaan moralitas publik, etika, dan norma-norma sebagaimana telah ditundukkan oleh budaya hedonistik cepat masyarakat modern, yang berkontribusi pada munculnya praktik prostitusi. Keempat, kurangnya komitmen dari pemerintah dan penegak hukum untuk mendisiplinkan praktik prostitusi. Terakhir, kurangnya layanan sosial dan bantuan publik terhadap orang-orang yang kurang berkembang. Karena penyebab di atas, prostitusi telah menjadi praktik berbahaya tidak hanya bagi masyarakat tetapi juga bagi pekerja seks yang rentan terhadap eksploitasi, diskriminasi, kekerasan, dan perlakuan tidak adil oleh hukum. Memang persepsi publik yang negatif, pada kenyataannya, berkontribusi pada diskriminasi yang tidak henti-hentinya terhadap pekerja seks. Dengan begitu negativitas mendorong penegakan disiplin oleh hukum terhadap prostitusi, seringkali, jika tidak selalu, bahwa tindakan tersebut tidak dapat menyelesaikan penyebab prostitusi, kurangnya perhatian pemerintah terhadap pengembangan orangorang ini. ${ }^{8}$ Tetapi sebaliknya, peraturan lokal yang ada mengatur hukuman

6Phil Hubbard, "Cleansing the Metropolis: Sex Work and the Politics of Zero Tolerance," Urban Studies 41, no. 9 (2004): 1687-1702, https://doi.org/10.1080/0042098042000243101; Hull, Sulistyaningsih, dan Jones, "Prostitution in Indonesia: Its History and Evolution"; Valerie Jenness, "From Sex as Sin to Sex as Work: COYOTE and the Reorganization of Prostitution as a Social Problem," Social Problems 37, no. 3 (Agustus 1990): 403-20, https://doi.org/10.1525/sp.1990.37.3.03a00090.

7Edlund dan Korn, "A Theory of Prostitution"; Alexandre Leal de Freitas, "Red Light at the Intersection: the Stigma of Sex Work and the Double Oppression Inflicted upon Trans Sex Workers" (Eötvös Loránd University, Budapest, 2016), https://doi.org/20.500.11825/164.

${ }^{8}$ Arivai Nazaruddin Sembiring et al., "Tindak Pidana Terkait Asusila Berdasarkan Hukum Pidana (KUHP) di Indonesia dan Syariat Islam di Aceh (Studi Penelitian di Kota Banda Aceh)," USU Law Journal 4, no. 2 (2016): 192-203, https://jurnal.usu.ac.id/index.php/law/article/view/13557. 
berat dan penegakan keras terhadap pelakunya yang bukan hanya para distributor tetapi juga para pekerja seks karena banyak alasan, yang kebanyakan adalah agama dan moralitas. ${ }^{9}$

Misalnya, Peraturan Kotamadya Tangerang No. 8/2005 melarang segala jenis praktik prostitusi dengan arti apa pun adalah tindakan seksual yang dilakukan dalam pergantian uang, dan Peraturan Kabupaten Indramayu No. 7/1999 tentang Pelacuran di mana setiap prostitusi pelaku -distributor dan pekerja seks- dapat dikenakan biaya. Selain itu, KUHP Indonesia (pasal 295, 296, 297, dan 506) juga menetapkan biaya pidana untuk mucikari atau distributor prostitusi. Namun sebaliknya, beberapa pemerintah daerah di Indonesia memilih melokalisasi prostitusi daripada melarang atau memberantasnya. Hal ini ditunjukkan di Kabupaten Kendal yang pemerintahnya telah memberlakukan Peraturan Kabupaten Kendal No. 8/2010 yang mengatur lokalisasi prostitusi ke ruang yang ditentukan di Alas Karet. Peraturan ini secara luas dihargai karena tujuan lokalisasi tersebut yang berkisar pada pengendalian HIV/AIDS, perlakuan yang manusiawi terhadap pekerja seks. Peraturan tersebut mengubah persepsi publik terhadap prostitusi sebagai sesuatu yang tidak dapat dihindarkan dan tidak mungkin diberantas karena mobilisasi dan persaingan yang cepat dari modal dan buruh yang selalu menjadi pasar preconditioning untuk prostitusi. ${ }^{10}$ Oleh karena itu, alih-alih memberantas prostitusi, pemerintah Kabupaten Kendal bermaksud melokalkannya di tempat yang ditentukan tanpa terpapar kehidupan sehari-hari masyarakat untuk menahan penyebaran ketidaksenonohan.

Namun, prostitusi baru-baru ini telah dipermasalahkan sekali lagi karena alasan politik. Tahap kontestasi yang terjadi di legislatif negara di mana RUU KUHP baru telah diajukan dan tergesa-gesa ke dalam dewan legislatif. RUU

\footnotetext{
${ }^{9}$ Melissa Amy Crouch, "Religious Regulations in Indonesia: Failing Vulnerable Groups?," Review of Indonesian and Malaysian Affairs 43, no. 2 (2009), https://papers.ssrn.com/sol3/papers.cfm? abstract_id=1601065; Riswanda, Corcoran-Nantes, dan McIntyre-Mills, "Re-framing Prostitution in Indonesia: ACritical Systemic Approach."

${ }^{10} \mathrm{~J}$. Godwin, Sex Work and the Law in Asia and the Pasific (Bangkok: United Nations Development Programme, 2012); Hubbard, "Cleansing the Metropolis: Sex Work and the Politics of Zero Tolerance"; Jenness, "From Sex as Sin to Sex as Work: COYOTE and the Reorganization of Prostitution as a Social Problem."
} 
KUHP bersifat kontroversial karena kejam, terutama dalam hal pidana kecabulan seksual seperti perzinaan.

Ketentuan perzinaan dalam RUU KUHP bertentangan dengan niat perlakuan yang manusiawi, kesetaraan, dan non-diskriminatif terhadap pekerja seks yang seharusnya dianggap sebagai korban eksploitasi, bukan pelaku kejahatan ketidaksenonohan. Prinsip keadilan restoratif yang mempromosikan inklusi sosial dan restorasi berbasis korban digantikan oleh prinsip retoris yang keras yang mengidealkan beratnya hukuman dan pengasingan sosial terhadap terpidana sebagai pelajaran publik sehingga kejahatan tersebut tidak akan terulang. Oleh karena itu, artikel ini akan mengeksplorasi kemungkinan implikasi dari RUU KUHP baru tentang pekerja seks yang akan dikritik untuk menyarankan metode alternatif untuk menangani pelacuran tanpa meremehkan hak asasi manusia dan martabat pekerja seks.

Untuk menganalisis seperti itu, artikel ini akan didasarkan pada metode penelitian pendekatan normatif hukum di mana undang-undang atau masalah hukum dianalisis melalui seperangkat hukum normatif yang ada. Selain itu, artikel ini akan menggabungkan penelitian hukum berbasis literatur dan dilengkapi dengan data kualitatif untuk menekankan masalah dalam RUU KUHP baru.

Kehidupan PSK tidak dapat dihindari dari perlakuan diskriminasi yang mereka hadapi setiap harinya. Tindakan diskriminasi yang sering dialami oleh PSK ini antara lain peraturan perundang-undangan mendiskriminasi PSK dengan melarang adanya praktek prostitusi membuat PSK menjadi suatu perbuatan yang dilarang tanpa memberikan solusi yang tepat apa yang harus dikerjakan oleh PSK sebagai sumber mata pencarian yang lebih layak. Dalam beberapa peraturan daerah (perda) di Indonesia seperti pada pasal 2 ayat 2 Perda Kota Tangerang No. 8 Tahun 2005 yang mengatur siapapun di daerah dilarang baik secara sendiri ataupun bersamasama untuk melakukan perbuatan pelacuran, kemudian pasal 7 Perda Kabupaten Indramayu No. 7 Tahun 1999 Pelaku Prostitusi baik laki-laki maupun perempuannya dikenakan sanksi, juga dalam pasal 296 KUHP, pasal 506 KUHP yang mengatur pidana terhadap mucikari yang mengambil keuntungan dari tindakan prostitusi, serta pasal 297, pasal 295, pasal 296 KUHP yang ditujukan bagi anak belum dewasa. Namun di 
sisi lain, di beberapa daerah terdapat kebijakan dari pemerintah daerah setempat untuk melokalisasi kegiatan prostitusi seperti pada Kabupaten Kendal yang mengeluarkan Perda Kabupaten No. 8 tahun 2010 yang mengatur mengenai lokalisasi PSK di area Alas Karet. Ketidak tegasan dalam menentukan apakah prostitusi merupakan kegiatan yang dilarang atau dilegalkan ini lah yang tidak mewujudkan kepastian hukum. Hal ini kemudian semakin diperparah dengan rumusan pasal dalam RKUHP yakni pada pasal 485 (1) yang menyatakan:

"Dipidana karena zina, dengan pidana penjara paling lama 5 (lima) tahun: a. laki-laki yang berada dalam ikatan perkawinan melakukan persetubuhan dengan perempuan yang bukan istrinya; b. perempuan yang berada dalam ikatan perkawinan melakukan persetubuhan dengan laki-laki yang bukan suaminya; c. laki-laki yang tidak dalam ikatan perkawinan melakukan persetubuhan dengan perempuan, padahal diketahui bahwa perempuan tersebut berada dalam ikatan perkawinan; d. perempuan yang tidak dalam ikatan perkawinan melakukan persetubuhan dengan laki-laki, padahal diketahui bahwa laki-laki tersebut berada dalam ikatan perkawinan; atau e. laki-laki dan perempuan yang masing-masing tidak terikat dalam perkawinan yang sah melakukan persetubuhan."

Rumusan pasal tersebut tentu berpotensi mengkriminalisasi perempuan yang dalam kasus prostitusi seharusnya merupakan korban yang diberi perlindungan dan diupayakan agar dapat kembali ke masyarakat.

Pendekatan masalah dan penelitian ini sesuai dengan pokok permasalahannya yaitu pendekatan yuridis normatif serta didukung dengan data primer lapangan sebagai pendukung. Untuk menganalisis seperti itu, artikel ini akan didasarkan pada metode penelitian pendekatan normatif hukum di mana undang-undang atau masalah hukum dianalisis melalui set hukum normatif yang ada." Selain itu, artikel ini akan menggabungkan penelitian hukum berbasis literatur dan dilengkapi dengan data kualitatif untuk menekankan masalah dalam RUU KUHP baru.

${ }^{11}$ Sulistyowati Irianto, ed, Metode Peneltian Hukum: Konstelasi dan Refleksi (Jakarta: Yayasan Pustaka Obor Indonesia, 2009), 15-19; Bambang Sunggono, Metode Penelitian Hukum (Jakarta: Raja Grafindo Persada, 1997), 33-34. 


\section{B. Kriminalisasi Perempuan Pekerja Seks Komersial dalam Perluasan Pasal Zina RUU KUHP}

Hukum merupakan salah satu sarana untuk menata ketertiban dalam masyarakat, tetapi ia tidak persis sama dengan ketertiban. Ketertiban mencakup hukum, tetapi hukum bukan satu-satunya cara atau jalan untuk menciptakan ketertiban. ${ }^{12}$ Kendati hanya menempati satu sudt saja dalam jagat ketertiban, namun hukum memiliki kekuatan yang begitu besar karena dibelakang hukum terdapat mesin kekuatan bernama Negara. ${ }^{13}$ Meskipun demikian, jagat ketertiban menampilkan kehadiran jaringan yang kompleks dengan menunjukan relasi antara hukum dan masyarakat sebab jagat ketertiban bertolak dari kenyataan dalam masyarakat. Sebagaimana disampaikan oleh peneliti Robert C. Ellickson, bahwa yang lebih menentukan bagaimana ketentuan dalam hukum itu diwujudkan bukanlah peraturan hukum itu sendiri, melainkan rakyat sebagai adresat dari hukum. ${ }^{14}$ Kekurangan berhati-hati dalam membuat hukum memiliki risiko bagwa hukum yang seharusnya membahagiakan masyarakat justru menyusahkan atau menimbulkan kerusakan dalam masyarakat. Hukum yang seperti ini memiliki potensi untuk menjadi kriminogen, sesuatu yang dalam istilah Prof Satjipto Rahardjo sebagai tragedi manusia dan hukumnya (2008: 10). ${ }^{15}$ Hal ini kemudian menjadi landasan untuk mencermati rumusan Pasal 485 (1) dalam RKUHP yang menyatakan

"Dipidana karena zina, dengan pidana penjara paling lama 5 (lima) tahun:

a. laki-laki yang berada dalam ikatan perkawinan melakukan persetubuhan dengan perempuan yang bukan istrinya;

b. perempuan yang berada dalam ikatan perkawinan melakukan persetubuhan dengan laki-laki yang bukan suaminya;

c. laki-laki yang tidak dalam ikatan perkawinan melakukan persetubuhan dengan perempuan, padahal diketahui bahwa perempuan tersebut berada dalam ikatan perkawinan;

\footnotetext{
${ }^{12}$ S. Rahardjo, Biarkan Hukum Mengalir (Jakarta: Kompas, 2008), 22.

${ }^{13}$ Rahardjo, 24.

${ }^{14}$ Rahardjo, 32.

${ }^{15}$ Rahardjo, 10; Sudarto, Hukum Pidana I (Semarang: Yayasan Sudarto, 1991).
} 
d. perempuan yang tidak dalam ikatan perkawinan melakukan persetubuhan dengan laki-laki, padahal diketahui bahwa laki-laki tersebut berada dalam ikatan perkawinan; atau

e. laki-laki dan perempuan yang masing-masing tidak terikat dalam perkawinan yang sah melakukan persetubuhan.".

Masalahnya terletak pada definisi perzinaan dalam pasal 485 ayat (1) RUU KUHP yang secara luas mencakup sejauh mana hukuman dari pasangan yang belum menikah. Selain itu, karena definisi perkawinan yang ketat - yang diputuskan dalam Undang-Undang Perkawinan-, RUU KUHP dapat secara tidak adil menghukum banyak orang yang melakukan tindakan seksual. Korban yang mungkin mungkin termasuk:

1) Jenis perkawinan yang tidak dikenal oleh negara seperti pernikahan adat, perkawinan beda agama, pernikahan berbasis agama dan pernikahan yang tidak bersyarat;

2) Pasangan kumpul kebo atau pasangan yang belum menikah yang tinggal bersama -dan diketahui telah melakukan tindakan seksual;

3) Tindakan seksual yang disetujui bersama atau didasari suka-sama-suka antara dua atau lebih orang;

4) Pekerja seks.

Poin e pasal 485 (1) RUU KUHP tentu saja dapat mengarah pada hukuman yang tidak adil -bahkan hukuman penjara- terhadap pekerja seks karena mereka mungkin telah melakukan tindakan seksual baik dengan klien yang sudah menikah atau yang tidak menikah. Berbeda dengan KUHP yang ada yang hanya menghukum distributor prostitusi, RUU KUHP baru dapat menghukum distributor, klien, dan juga pekerja seks. Selain itu, perempuan cenderung lebih didiskriminasi dan mengalami perlakuan tidak adil oleh hukum karena prostitusi perempuan sangat menonjol. Selain itu, banyak pelacur perempuan yang telah didisiplinkan oleh penegak hukum karena ketidaksenonohan publik sering menjadi korban karena perlakuan kasar, diskriminasi sosial, dan kekerasan. Perlakuan negatif seperti itu sering didahului oleh struktur sosial yang buruk yang mendorong penyimpangan perilaku moral dan bukannya penyelarasan dengan norma-norma sosial yang ada. 
Banyak dari kejahatan ini mempengaruhi elemen ekonomi dan sosial yang memiliki peran dalam pengembangan prostitusi. Banyak faktor dalam masyarakat membuktikan bahwa orang miskin ditekan untuk kebutuhan ekonomi. Dalam hal ini, pelacur dipaksa menghasilkan uang, baik wanita maupun pria. Fakta sosial ini menunjukkan bahwa sebagian besar perempuan menjadi pelacur tidak semata-mata karena keserakahan atau keinginan untuk hidup dalam kemewahan, tetapi karena faktor-faktor lain seperti ekonomi, keluarga, kemiskinan, bahkan konstruksi sosial yang memungkinkan bisnis prostitusi berlanjut. ${ }^{16}$ Ketidakpastian pemerintah dalam memerangi pelacuran kemudian menjadi salah satu faktor dominan mengapa bisnis prostitusi tetap di Indonesia. Ironisnya, meskipun bisnis ini dianggap sebagai penyimpangan dari norma dan nilai, ternyata bisnis ini dianggap legal dan legal berdasarkan norma-norma positif. Apayang terjadi di pelacuran Dolly di Surabaya, misalnya, adalah salah satu bentuk nyata bagaimana prostitusi adalah legal di beberapa daerah, diberikan izin oleh pemerintah setempat. ${ }^{17}$ Ini menunjukkan bahwa ada ketidakpastian hukum oleh negara dalam menangani prostitusi.

Kementerian Sosial telah mengambil tindakan pencegahan untuk meminimalkan -jika tidak melenyapkan-prostitusi melalui pengumuman "Indonesia Action Free of Prostitution 2019." Kementerian Sosial mengintegrasikan kebijakan publik, aksi publik, dan dukungan untuk organisasiorganisasi mitra di bawah salah satu tujuan pemberantasan praktek prostitusi. ${ }^{18}$ Retorikanya sering tentang keberadaan prostitusi sebagai manifestasi perilaku menyimpang yang secara moral dan etis tidak sesuai dengan nilai ideologi nasional, Pancasila, untuk mengeksploitasi dan meremehkan martabat perempuan. Dinyatakan juga bahwa prostitusi adalah produk patriarki dan

\footnotetext{
${ }^{16}$ Contoh yang relevan dengan peristiwa di Indonesia bisa dibandingkan dengan Freitas, "Red light at the intersection: the stigma of sex work and the double oppression inflicted upon trans sex workers." dimana pelacuran Eropa Barat mengeksploitasi perempuan melalui trafficking terhadap perempuan-perempuan korban perang Yugoslavia.

${ }^{17}$ Atikah Amirah, "Cultural, Social, and Economic Perspectives in Making a Criminal Policy (Dolly Prostitution)," The Journal of Macro Trends in Social Science 1, no. 1 (2015): 45-53, http://www.merdeka.com/peristiwa/kisah-tante-dolly-dan-legenda-gang-prostitusi-di-surabaya.html.

${ }^{18}$ Godwin, Sex Work and the Law in Asia and the Pasific; Sembiring et al., "Tindak Pidana Terkait Asusila Berdasarkan Hukum Pidana (KUHP) di Indonesia dan Syariat Islam di Aceh (Studi Penelitian di Kota Banda Aceh)"; Sibuea, “Penegakan Hukum Prostitusi di Indonesia.”
} 
seksisme yang mengancam posisi perempuan dalam masyarakat. Budaya patriarki jelas menempatkan posisi perempuan jauh lebih rendah daripada laki-laki dan menempatkan perempuan sebagai objek bahkan dalam kasus prostitusi dapat diperdagangkan. Budaya patriarki ini sengaja diabadikan dalam masyarakat. Menurut teori gender dari Simone de Beauvoir dan Judith Butler, penindasan adalah salah satu produk sampingan dari budaya patriarkal. ${ }^{19}$ Ini juga berkorelasi dengan kehadiran prostitusi. Konstruksi budaya yang menempatkan posisi perempuan yang lebih rendah kemudian melanggengkan bisnis prostitusi yang tampaknya tidak hanya masuk ke dalam pikiran mucikari, pelanggan dan wanita yang menyerah untuk menjadi pekerja seks semata, tetapi telah merambah ke dalam politik dengan adanya peraturan lokal Sayangnya, ketika prostitusi seharusnya diberantas sampai akarnya, RUU KUHP sebagai cerminan dari hukum pidana nasional sebenarnya membuat pengaturan yang bias gender dengan menempatkan perempuan yang sering menjadi korban prostitusi sebagai pihak yang bersalah. Meskipun seharusnya menghapus prostitusi, pihak-pihak yang harus ditangani dengan tegas adalah germo dan pelanggan dari bisnis prostitusi. Hingga saat ini, tidak ada artikel yang ditujukan untuk pengguna layanan prostitusi. Bahkan, salah satu faktor yang menyebabkan bisnis ini terus ada tentu karena ada kebutuhan untuk pelanggan prostitusi. Sangat tidak adil jika perempuan yang menjadi korban atau objek penjualan kemudian dihukum, sementara tidak semua pihak yang berdagang diberi sanksi tegas.

Hukum harus peka terhadap situasi transisional di sekitarnya. Menurut Teubner, hukum tidak hanya dituntut untuk menjadi sistem terbuka, tetapi juga

\footnotetext{
${ }^{19}$ Judith Butler menyebut ini sebagai performatifitas gender dimana stigma-stigma identitas gender dikonstruksi oleh pengaruh-pengaruh sosial, kultur, dan perilaku masyarakat yang bersinggungan. Untuk lebih lanjut lihat di Judith Butler, "Performative Acts and Gender Constitution: An Essay in Phenomenology and Feminist Theory," Theatre Journal 40, no. 4 (1988): 519-31, https://philpapers.org/rec/BUTPAA; Anoop Nayak dan Mary Jane Kehily, "Gender Undone: Subversion, Regulation and Embodiment in the Work of Judith Butler," British Journal of Sociology of Education 27, no. 4 (2006): 459-72, https://doi.org/10.1080/01425690600803038; Untuk lebih lanjut mengenai teori gender dari Simone de Beauvoir, lihat: Sonia Kruks, "Gender and Subjectivity: Simone de Beauvoir and Contemporary Feminism," Signs: Journal of Women in Culture and Society 18, no. 1 (992): 89-110, https://doi.org/10.2307/3174728; Simone DE. Beauvoir, Second Sex: Fakta dan Mitos (Yogyakarta: Pustaka Promethea, 1989).
} 
harus bergantung pada kedaulatan tujuan, yaitu tujuan sosial yang ingin dicapai dan konsekuensi yang timbul dari pengoperasian hukum. ${ }^{20}$ Ada dua indikator bahwa undang-undang tersebut responsif terhadap masalah sosial yang terjadi di masyarakat. Pertama, hukum harus fungsional, pragmatis, objektif, dan rasional. Kedua, kompetensi adalah patokan untuk mengevaluasi semua penegakan hukum. Tetapi dalam melihat kasus-kasus prostitusi dan adanya perluasan pasal perzinaan dalam RUU KUHP, ini tidak menunjukkan responsivitas hukum. Undang-undang yang seharusnya bertujuan untuk memecahkan masalah sebenarnya menciptakan masalah baru yang terkait dengan hak asasi perempuan pekerja seks perempuan. Akibatnya, undangundang semacam itu hanyalah lembaga buatan dan semakin menjauhkan dari masyarakat atau masyarakat dan tidak sesuai dengan cita-cita hukum di masyarakat. Seharusnya hukum untuk manusia dan bukan sebaliknya, jika manusia adalah untuk hukum, maka dinamika masyarakat akan terhambat, tetapi jika hukum adalah untuk manusia, maka seharusnya tidak menjadi hambatan untuk menjadi dinamika masyarakat. Karena alasan ini, negara sebagai organisasi komunitas dan mesin hukum yang kuat tidak boleh membentuk undang-undang yang bias gender seperti dalam Pasal 485 RUU KUHP, tetapi masih memberantas prostitusi, merehabilitasi dan mengintensifkan program pemberdayaan mantan pekerja seks. Swedia dapat menjadi referensi ideal bagi Indonesia untuk mengatasi prostitusi yang saat ini begitu merajalela. Sejak UU Anti-Prostitusi diberlakukan pada prostitusi di Swedia. Penurunan ini karena UU Anti-Prostitusi yang berlaku menghukum pengguna layanan prostitusi dengan mempublikasikan identitas mereka di media massa dan mereka yang tertangkap wajib membayar denda substansial atau 6 (enam) bulan penjara. Kemudian Undang-undang menganggap pekerja seks sebagai korban eksploitasi, sehingga UU tidak akan menghukum mereka, tetapi mereka yang dituntut oleh pengguna layanan prostitusi. Bagi mereka, prostitusi adalah bentuk kekerasan laki-laki terhadap perempuan. Menariknya, UU AntiProstitusi Swedia juga menyediakan dana layanan sosial untuk membantu

${ }^{20}$ Gunther Teubner, "Substantive and Reflexive Elements in Modern Law," Law \& Society Review 17, no. 2 (1983): 239-86, https://doi.org/10.2307/3053348. 
pekerja seks yang ingin pensiun. Keberhasilan Swedia juga diadopsi oleh Finlandia, Norwegia, Islandia, Skotlandia, dan akhirnya Prancis.

Saat ini Kementerian Sosial menunjuk sebuah divisi untuk menangani reintegrasi sosial dan rehabilitasi sosial yaitu Direktorat Jenderal Rehabilitasi Sosial terhadap pekerja seks. Mandat ini diatur dalam UU No. 11/2009 tentang Kesejahteraan Sosial, khususnya pasal 7 ayat (1). Dalam artikel tersebut, ditetapkan bahwa "rehabilitasi sosial dimaksudkan untuk memperkuat dan mengembangkan kapasitas seseorang yang mengalami disfungsi sosial sehingga kemampuan seseorang dapat dimanfaatkan dengan semestinya." Contohnya ditunjukkan dari kotamadya Batam yang memiliki Pusat Rehabilitasi Sosial Non-Residen di Tanjungpandan, Surakarta dan Surabaya kotamadya yang diberlakukan lokakarya dan bantuan kewirausahaan untuk pekerja seks. Keterampilan harus dimiliki oleh seseorang untuk menangani masalah atau masalah hidup sehingga mereka dapat hidup adil dalam hidup mereka. Program keterampilan dimaksudkan untuk memberikan ketentuan bagi pekerja seks yang terkait dengan kebutuhan pasar kerja, peluang bisnis, potensi ekonomi atau industri di masyarakat. Keterampilan diberikan untuk meningkatkan pengetahuan dan sikap belajar warga di lapangan yang sesuai dengan kebutuhan, bakat dan minat mereka sehingga mereka memiliki bekal untuk bekerja secara mandiri untuk dapat meningkatkan kualitas hidup mereka. Ini jauh lebih memanusiakan manusia daripada menjatuhkan sanksi pidana sebagai "obat terakhir" yang seharusnya menjadi sarana terakhir ketika langkah-langkah lain tidak dapat dicapai sehingga penggunaannya harus dihindari.

\section{Kesimpulan}

Praktek prostitusi adalah fenomena lama yang telah ada sejak keberadaan peradaban manusia, tidak terkecuali di Indonesia. Hingga saat ini, masih belum ada sistem hukum di Indonesia terkait dengan pemberantasan prostitusi. Dalam menanggapi hal ini, negara berusaha untuk bergerak secara responsif terhadap masalah-masalah sosial ini, salah satunya diupayakan melalui kelahiran artikel tentang prostitusi dan perluasan ketentuan perzinaan dalam RUU KUHP yang sayangnya tidak hanya menargetkan pengguna dan germo, 
tetapi berpotensi mengancam pekerja seks sebagai korban. Negara harus menjadi organisasi masyarakat dan mesin besar kekuasaan untuk hukum yang tidak merumuskan undang-undang yang bias gender seperti dalam Pasal 485 RUU KUHP, tetapi masih memberantas prostitusi, merehabilitasi dan mengintensifkan program pemberdayaan perempuan untuk pekerja seks.[s]

\section{Daftar Pustaka}

Amirah, Atikah. "Cultural, Social, and Economic Perspectives in Making a Criminal Policy (Dolly Prostitution)." The Journal of Macro Trends in Social Science 1, no. 1 (2015): 45-53. http://www.merdeka.com/peristiwa/kisah-tantedolly-dan-legenda-gang-prostitusi-di-surabaya.html.

Beauvoir, Simone DE. Second Sex: Fakta dan Mitos. Yogyakarta: Pustaka Promethea, 1989.

Butler, Judith. "Performative Acts and Gender Constitution: An Essay in Phenomenology and Feminist Theory." Theatre Journal 40, no. 4 (1988): 519-31. https://philpapers.org/rec/BUTPAA.

Crouch, Melissa Amy. "Religious Regulations in Indonesia: Failing Vulnerable Groups?" Review of Indonesian and Malaysian Affairs 43, no. 2 (2009). https://papers.ssrn.com/sol3/papers.cfm?abstract_id=1601065.

Ditmore, M. H. Encyclopedia of Prostitution and Sex Work. Vol. 1. California: Greenwood Publishing, 2006.

Edlund, Lena, dan Evelyn Korn. "A Theory of Prostitution." Journal of Political Economy 110, no. 1 (2002): 181-214. https://doi.org/10.1086/324390.

Freitas, Alexandre Leal de. "Red light at the intersection: the stigma of sex work and the double oppression inflicted upon trans sex workers." Eötvös Loránd University, Budapest, 2016. https://doi.org/20.500.11825/164.

Gilfoyle, Timothy J. "Prostitutes in History: From Parables of Pornography to Metaphors of Modernity." The American Historical Review 104, no. 1 (1999): 117-41. https://doi.org/10.2307/2650183.

Godwin, J. Sex Work and the Law in Asia and the Pasific. Bangkok: United Nations Development Programme, 2012. 
Hubbard, Phil. "Cleansing the Metropolis: Sex Work and the Politics of Zero Tolerance." Urban Studies 41, no. 9 (2004): 1687-1702. https://doi.org/ 10.1080/0042098042000243101.

Hull, Terence H., E. Sulistyaningsih, dan G. Jones. "Prostitution in Indonesia: Its History and Evolution." Bulletin of Indonesian Economic Studies 36, no. 1 (2000): 258-60.

Irianto, Sulistyowati, ed. Metode Peneltian Hukum: Konstelasi dan Refleksi. Jakarta: Yayasan Pustaka Obor Indonesia, 2009.

Jenness, Valerie. "From Sex as Sin to Sex as Work: COYOTE and the Reorganization of Prostitution as a Social Problem." Social Problems 37, no. 3 (Agustus 1990): 403-20.https://doi.org/10.1525/sp.1990.37.3.03a00090.

Kruks, Sonia. "Gender and Subjectivity: Simone de Beauvoir and Contemporary Feminism." Signs: Journal of Women in Culture and Society 18, no. 1 (992): 89-110. https://doi.org/10.2307/3174728.

Nayak, Anoop, dan Mary Jane Kehily. "Gender Undone: Subversion, Regulation and Embodiment in the Work of Judith Butler." British Journal of Sociology of Education 27, no. 4 (2006): 459-72. https://doi.org/10.1080/ 01425690600803038.

Rahardjo, S. Biarkan Hukum Mengalir. Jakarta: Kompas, 2008.

Riswanda, Yvonne Corcoran-Nantes, dan Janet McIntyre-Mills. "Re-framing Prostitution in Indonesia: A Critical Systemic Approach." Systemic Practice and Action Research 29, no. 6 (2016): 517-39. https://doi.org/10.1007/s11213-016-9379-2.

Riswanda, Janet McIntyre-Mills, dan Yvonne Corcoran-Nantes. "Prostitution and Human Rights in Indonesia: A Critical Systemic Review of Policy Discourses and Scenarios." Systemic Practice and Action Research 30, no. 3 (2017): 21337. https://doi.org/10.1007/s11213-016-9393-4.

Sembiring, Arivai Nazaruddin, Mahmud Mulyadi, Muhammad Ekaputra, dan Rosnidar Sembiring. "Tindak Pidana Terkait Asusila Berdasarkan Hukum Pidana (KUHP) di Indonesia dan Syariat Islam di Aceh (Studi Penelitian di Kota Banda Aceh)." USU Law Journal 4, no. 2 (2016): 192-203. https://jurnal.usu.ac.id/index.php/law/article/view/13557.

Sibuea, Harris Y. P. "Penegakan Hukum Prostitusi di Indonesia." Info Singkat Hukum: Kajian Singkat terhadap Isu Aktual Stategis 7, no. 10 (2015). www.dpr.go.id. 
Kriminalisasi Perempuan Pekerja Seks Komersial .....

Sudarto. Hukum Pidana I. Semarang: Yayasan Sudarto, 1991.

Sunggono, Bambang. Metode Penelitian Hukum. Jakarta: Raja Grafindo Persada, 1997.

Teubner, Gunther. "Substantive and Reflexive Elements in Modern Law." Law \& Society Review 17, no. 2 (1983): 239-86. https://doi.org/10.2307/3053348. 
This page intentionally left blank 